\title{
Hepatoprotective effects of litchi (Litchi chinensis) procyanidin A2 on carbon tetrachloride-induced liver injury in ICR mice
}

\author{
LIH-GEENG CHEN $^{1}$, CHENG-WEI CHANG $^{1}$, JWU-GUH TSAY $^{2}$ and BRIAN BOR-CHUN WENG ${ }^{1}$ \\ ${ }^{1}$ Department of Microbiology, Immunology and Biopharmaceutics, College of Life Sciences, \\ National Chiayi University, Chiayi 60004; ${ }^{2}$ Department of Hospitality, College of Applied Life, \\ Nan Jeon University of Science and Technology, Tainan 73746, Taiwan, R.O.C.
}

Received December 8, 2015; Accepted December 23, 2016

DOI: $10.3892 / \mathrm{etm} .2017 .4358$

\begin{abstract}
Drug tolerance, lacking liver regenerative activity and inconclusive inhibition of steatosis and cirrhosis by silymarin treatment during chronic liver injury have increased the demand for novel alternative or synergistic treatments for liver damage. Litchi fruit is abundant in polyphenolic compounds and is used in traditional Chinese medicine for treatments that include the strengthening of hepatic and pancreatic functions. Unique polyphenolic compounds obtained from litchi pericarp extract (LPE) were studied in vitro and in vivo for hepatoprotection. Epicatechin (EC) and procyanidin A2 (PA2) of LPE were obtained by fractionated-extraction from pulverized litchi pericarps. All fractions, including LPE, were screened against silymarin in carbon tetrachloride $\left(\mathrm{CCl}_{4}\right)$-treated murine embryonic liver cell line (BNL). The effects of daily gavage-feeding of LPE, silymarin $(200 \mathrm{mg} / \mathrm{kg}$ body weight) or $\mathrm{H}_{2} \mathrm{O}$ in $\mathrm{CCl}_{4}$-intoxicated male ICR mice were evaluated by studying serum chemicals, liver pathology and glutathione antioxidative enzymes. The effects of EC and PA2 on liver cell regenerative activity were investigated using a scratch wound healing assay and flow cytometric cell cycle analysis; the results of which demonstrated that LPE protected $\mathrm{BNL}$ from $\mathrm{CCl}_{4}$-intoxication. Gavage-feeding of LPE decreased serum glutamic oxaloacetate transaminase and
\end{abstract}

Correspondence to: Professor Brian Bor-Chun Weng, Department of Microbiology, Immunology and Biopharmaceutics, College of Life Sciences, National Chiayi University, 300 University Road, Chiayi 60004, Taiwan, R.O.C.

E-mail: brian@mail.ncyu.edu.tw

Abbreviations: BNL, BNL CL2 murine embryonic liver cell line; LPE, litchi pericarp extract derived from D40M fraction; A/G, albumin/globulin; $\mathrm{CCl}_{4}$, carbon tetrachloride; GOT, glutamic oxaloacetate transaminase; GPT, glutamic pyruvic transaminase; T-Chol, total cholesterol; T-p, total protein; T-bili, total bilirubin; TG, triglyceride; GSHpx, glutathione peroxidise; GSHred, glutathione reductase; EC, epicatechin; PA2, procyanidin A2

Key words: carbon tetrachloride, litchi, lychee, liver injury, procyanidin, epicatechin, hepatoprotection glutamic pyruvic transaminase levels, and exhibited superior retention of the hexagonal structure of hepatocytes and reduced necrotic cells following liver histopathological examinations in $\mathrm{CCl}_{4}$ intoxicated ICR mice. Glutathione peroxidise and glutathione reductase activities were preserved as the normal control level in LPE groups. EC and PA2 were principle components of LPE. PA2 demonstrated liver cell regenerative activity in scratch wound healing assays and alcohol-induced liver cell injury in vitro. The present findings suggest that litchi pericarp polyphenolic extracts, including EC and PA2, may be a synergistic alternative to silymarin in hepatoprotection and liver cell regeneration.

\section{Introduction}

Oxidative stress is a primary cause of toxic hepatitis and may result in chronic liver disease. Carbon tetrachloride $\left(\mathrm{CCl}_{4}\right)$-induced hepatotoxicity is widely used, experimentally, as a chemical toxicant for rapid induction of liver injury and the creation of liver fibrosis models of chronic liver damage. $\mathrm{CCl}_{4}$ induces liver injury through the destruction of the microsomal triglyceride transfer protein and through the metabolism of hepatic microsomal liver cytochrome P450, which produces free radicals and, ultimately, results in liver cell injury and inflammation (1).

Milk thistle, which is an antioxidative plant, produces silymarin containing four flavonolignan isomers (silybin, isosilybin, silydianin and silychristin). Silymarin is currently the first-line prescribed drug in clinics for the treatment of various symptoms of hepatitis. Silymarin has been reported to exhibit hepatoprotection due to its antioxidant and anti-inflammatory properties (2) and through the stimulation of protein synthesis, resulting in decreased serum glutamic oxaloacetate transaminase (GOT) and glutamic pyruvic transaminase (GPT) levels. However, drug tolerance (3) and inconsistent outcomes in the inhibition of liver fibrosis and steatosis (4) have hindered silymarin efficacy. Therefore, there is an increasing demand for novel alternative treatments to cure liver diseases or to use as synergistic health supplements for liver protection. Recently, B type procyanidin extract, primarily from grape seeds (5), and anthocyanidins (6) have exhibited effective inhibition of liver fibrosis and steatosis. 
Litchi fruit, a member of the Sapindaceae family, is abundant in polyphenolic compounds and is commonly used as a Chinese traditional herbal ingredient for liver tonics to strengthen hepatic and pancreatic functions (7). Fruit pericarp and seeds have been reported to possess anti-inflammatory and anti-carcinogenic properties $(8,9)$. Polyphenolic compounds, such as anthocyanins, tannins and many other ortho-diphenolic compounds, have been identified recently $(10,11)$. Further investigation in controlled studies is required for the evaluation of the unique polyphenolic contents of litchi for medicinal purposes and efficacy in hepatoprotection. Therefore, the present study investigated the hepatoprotective properties of litchi pericarp extract in vitro and in vivo liver injury models.

\section{Materials and methods}

Ethics statement. Laboratory animal protocols performed in the present study were in compliance with the regulations of the Institutional Animal Care and Use Committee (IACUC), National Chiayi University (Chiayi, Taiwan). All animal experimentations and protocols were approved by the IACUC.

Materials, isolation, purification and identification of bioactive compounds in litchipericarp. Pulverized pericarps of Litchi chinensis Sonn. fruit were extracted with methanol (41; $\mathrm{x} 2$ ), and the solution was filtered. The filtrate was concentrated by evaporation and, subsequently, freeze-dried to yield the litchi pericarp methanol extract $(280 \mathrm{~g})$. A $100 \mathrm{-g}$ portion of the methanol extract was dissolved in water and subjected to chromatography over a Diaion HP-20 column $(9.5 \times 82 \mathrm{~cm}$; Mitsubishi Chemical Corporation, Tokyo, Japan) with proportion of water to methanol $(0,20,40$ and $60 \%$ methanol) and final elute with $70 \%$ acetone to yield five fractions. From the five fractions, $40 \%$ methanol elute (LPE) was screened for bioactivity and subjected to further chromatography using Waters high-performance liquid chromatography equipment (Waters Corp., Milford, MA, USA) in settings and conditions described in the study by Chang (12). LPE was subjected to chromatography using a LiChroprep RP-18 column $(2.5 \mathrm{~cm}$ i.d.x51 cm; Merck Millipore, Darmstadt, Germany) from which five sub-fractions, of $10 \mathrm{~g}$ each, were derived. Sub-fractions one and two underwent additional LiChroprep RP-18 column chromatography to yield compound A, epicatechin, [EC; 71.2 $\mathrm{mg} ; \mathrm{C}_{15} \mathrm{H}_{14} \mathrm{O}_{6}$; molecular weight (MW), 290.27] and compound $\mathrm{B}$, procyanidin $\mathrm{A} 2$ (PA2; $168.5 \mathrm{mg} ; \mathrm{C}_{30} \mathrm{H}_{24} \mathrm{O}_{12} ; \mathrm{MW}, 576.50$ ), respectively. The chemical structures of the two compounds were originally identified by nuclear magnetic resonance (NMR; Bruker Avance DRX 500 instrument), conducted according to the study by Chang (12).

\section{In vitro assessments}

Cell culture. The murine embryonic liver BNL CL2 cell line (BNL; \#60180) and the monocyte/macrophage RAW264.7 cell line (RAW; \#60001) were obtained from the Bioresource Collection and Research Center (Hsinchu, Taiwan). All cell lines were maintained in RPMI-1,640 supplemented with $10 \%$ fetal bovine serum, $100 \mathrm{mg} / \mathrm{l}$ streptomycin, and $100 \mathrm{U} / \mathrm{ml}$ penicillin (Sigma-Aldrich; Merck Millipore) at $37^{\circ} \mathrm{C}$ and $5 \% \mathrm{CO}_{2}$ in a humidified incubator. Cell culture plastics were purchased from Corning Inc., (Corning, NY, USA). Chemicals were purchased from Sigma-Aldrich (Merck Millipore).

Rescue cell viability of $\mathrm{CCl}_{4}$-injured $\mathrm{BNL}$ CL2 cells. Assessment of the cytotoxicity of LPE on BNL and RAW264.7 monocytic cell lines was conducted with both 3-(4-, 5-dimethylthiazol-2-yl)-2,5-diphenyltetrazolium bromide (MTT) and lactate dehydrogenase ( $\mathrm{LDH}$; both Sigma-Aldrich; Merck Millipore) release assays, as described previously (13). LPE did not exhibit any cytotoxicity at the maximum concentration of $200 \mu \mathrm{g} / \mathrm{ml}$ (cytotoxicity data not shown). Rescued cell viability was performed by LDH release assay. Briefly, $1 \times 10^{6}$ cells $/ \mathrm{ml}(200 \mu \mathrm{l})$ were seeded onto 96-well culture plates overnight at $37^{\circ} \mathrm{C}$ and in a humidified incubator containing $5 \% \mathrm{CO}_{2}$. LPE was subsequently added at concentrations of $6.25,12.5,50$, and $100 \mu \mathrm{g} / \mathrm{ml}$ for a further $24 \mathrm{~h}$ incubation at $37^{\circ} \mathrm{C}$, in a humidified incubator containing $5 \% \mathrm{CO}_{2}$. Subsequently, $20 \mu \mathrm{l}$ MTT reagent or $50 \mu 1 \mathrm{LDH}$ reagents, including $0.2 \mathrm{M}$ Tris/ $\mathrm{HCl}$ buffer containing $0.0054 \mathrm{M}$ $\mathrm{L}$-(+)-lactic acid, $1.3 \mathrm{mM} \beta$-nicotinamide adenine dinucleotide, 0.66 mM 2-p-iodophenyl-3-p-nitrophenyl-5-phenyl tetrazolium chloride and $0.28 \mathrm{mM} \mathrm{N}$-methylphenazonium methyl sulfate (all Sigma-Aldrich; Merck Millipore) were added to each well for $30 \mathrm{~min}$ incubation at room temperature in the dark. Stop solution (1 $\mathrm{M}$ acetic acid) was then added and briefly mixed to allow for colorimetric detection. The specific absorbance at $570 \mathrm{~nm}$ for MTT assay and $490 \mathrm{~nm}$ for LDH assay were detected using a 96-well plate ELISA reader (BioTek Instruments, Inc., Winooski, UT, USA). To determine the liver cell protecting effect of $\mathrm{LPE}$ on $\mathrm{CCl}_{4}$-induced cell injury in vitro, BNL cells were treated with $10 \mathrm{nM} \mathrm{CCl}_{4}$ (in dimethyl sulfoxide) for $1 \mathrm{~h}$ prior to treatment with LPE at concentrations of 6.25, 12.5, 50, or $100 \mu \mathrm{g} / \mathrm{ml}$ or medium only. Silymarin at $50 \mu \mathrm{g} / \mathrm{ml}$ was used for positive control.

Scratch wound healing assay. The methodology was modified from the study performed by Liang et al (14). BNL cells were seeded in a 24-well plate and cultured in the same conditions described previously. Subsequently, a fixed tip width disposable plastic cell scraper was scratched across the cell monolayer, creating a gap in each well. Following this, EC, PA2 or silymarin were randomly assigned to the 24 wells for an additional 48-h culture. Images were captured, using a CCD-equipped inverted microscope, of the ability of the BNL cells to fill the gap. Images were analyzed for the cell-free area $\left(\mathrm{mm}^{2}\right)$ by Image Pro-Plus 5.0 (Media Cybernetics, Inc., Rockville, MD, USA).

Flow cytometry analysis of cell integrity and cell cycle of alcohol-injured BNL cells. Confluence BNL cells were pre-treated in medium containing $10 \%$ alcohol for $1 \mathrm{~h}$ at $37^{\circ} \mathrm{C}$. Subsequently, the cell culture was washed twice and placed in fresh medium. Following a $37^{\circ} \mathrm{C}$ overnight culture in normal media containing no treatment, or media containing 1, 5, 10,25 or $50 \mu \mathrm{g} / \mathrm{ml}$ PA2, the cells were harvested and fixed with $70 \%$ ethanol and stored overnight at $4^{\circ} \mathrm{C}$ for subsequent flow cytometry. Prior to acquisition, cells were centrifuged and stained by adding propidium iodide solution. Following staining for $30 \mathrm{~min}$, the samples were vortexed and ready for cell acquisition of at least 10,000 cells. Data were analyzed using WinMDI free software. 
$\mathrm{CCl}_{4}$-intoxicated mouse liver-injury model

Animals. A total of 48 8-week old male ICR mice were weighed (initial body weight, $28 \pm 0.54 \mathrm{~g}$ ) and randomly assigned to the normal control (house-keeping control) and $\mathrm{CCl}_{4}$-intoxicated treatment groups. Mice were housed in a temperature controlled environment at $23 \pm 1^{\circ} \mathrm{C}$ with a $12-\mathrm{h}$ light/dark cycle. The basal diet was using commercial rodent diet (Labdiet, St. Louis, MO, USA). Water and feed were provided ad libitum throughout the experiment. The treatment groups included: Distilled water $\left(\mathrm{H}_{2} \mathrm{O}\right)$ vehicle control; silymarin [200 mg/kg body weight (BW)/day]; and three levels of LPE (20, 100, and $200 \mathrm{mg} / \mathrm{kg} \mathrm{BW/day).} \mathrm{With} \mathrm{the} \mathrm{exception} \mathrm{of}$ the normal control group, all treatments were orally administered every morning. For $\mathrm{CCl}_{4}$ intoxication, mice were injected with $10 \mu \mathrm{lCl}_{4}(80 \% \mathrm{v} / \mathrm{v}$ in olive oil) intraperitoneally during the afternoon on Monday and Thursday, twice a week for an entire 6-week period.

Serum biochemical analyses. Peripheral blood samples were collected in heparinized haematocrit tubes. Serum was obtained by brief spin-down of blood samples. Biochemical analysis was conducted on serum samples at 1,3 and 6 weeks. Serum aspartate aminotransferase (GOT, also known as aspartate amino transferase), alanine aminotransferase (GPT, also known as alanine amino tranferase), total cholesterol (T-Chol), total protein (T-p), albumin, globulin, total bilirubin (T-bili), and triglycerides (TG) were analyzed using kits employing photometrical methods with a blood autoanalyser (Roche Cobas Mira Plus; Roche Diagnostics, Basel, Switzerland). Quantitative determinations were obtained within established limits. The referenced ranges of all analyzed parameters were taken from the study by Quimby and Luong (15). Serum analysis was also conducted on normal control group mice that were not treated with $\mathrm{CCl}_{4}$. Statistical comparisons were performed with data collected from the animals with $\mathrm{CCl}_{4}$-induced liver injury.

Gross liver examinations and histopathology assessments. Following animal experimentation, animals were euthanized via $\mathrm{CO}_{2}$ overdose, which first induced unconsciousness prior to sacrifice. Entire liver from the animals in each treatment group were harvested, weighed and immediately immersed in $37 \%$ formaldehyde (Thermo Fisher Scientific, Inc., Waltham, MA, USA). Forlmaldehyde was replaced with fresh formaldehyde at $48 \mathrm{~h}$. Liver tissues were sampled by taking vertical cross section of the largest liver lobe (lobus sinister lateralis heptis). Samples were subsequently embedded in paraffin. Tissue blocks were sliced into $5-\mu \mathrm{m}$ sections, layered onto glass slides and subsequently stained with haematoxylin and eosin for microscopic assessment. Tissue sectioning and staining were performed by the Animal Technology Laboratories at the Agricultural Technology Research Institute (Miaoli, Taiwan).

Liver antioxidative enzyme activity. An aliquot of fresh liver sample $(\sim 0.2 \mathrm{~g})$ was collected from each animal and stored at $-86^{\circ} \mathrm{C}$ until analysis. Samples were weighed and homogenized in a cold-water bath by adding $1 \mathrm{M}$ PBS (containing 1\% anhydrous ethanol and 1\% Triton X-100). Protein concentration was quantified via the Lowry assay using a Protein Quantification kit (\#PE0021; Gene Research
Lab Co., Ltd., Taipei, Taiwan) following centrifugation at $1,000 \times \mathrm{g}$ for $10 \mathrm{~min}$ at $4^{\circ} \mathrm{C}$. Subsequently, samples were justified for equal protein concentration. The glutathione peroxidase (GSHpx) and reductase (GSHred) activities of the tissue samples were determined using a Glutathione Peroxidase Assay kit (\#703102) and a Glutathione Reductase Assay kit (\#703202; Cayman Chemical Company, Ann Arbor, MI, USA) according to the manufacturer's instructions. The rate of change of absorbance (optical density, $340 \mathrm{~nm}$ ) per minute was expressed as $\mathrm{nmol} / \mathrm{min} / \mathrm{ml}$.

Statistical analysis. All data were expressed as the mean \pm standard deviation and analyzed using one-way analysis of variance (SAS Institute Inc., Cary, NC, USA). Treatment comparisons were performed using Duncan's multiple tests. $\mathrm{P}<0.05$ was considered to indicate a statistically significant difference.

\section{Results and Discussion}

LPE increases cell viability of $\mathrm{CCl}_{4}$-injured $\mathrm{BNL} C \mathrm{CL} 2$ liver cells in vitro. The D40M fraction (LPE) was fractionated from litchi pericarps using a LiChroprep RP-18 column and was subjected to chromatography as shown in Fig. 1A. The LPE was enriched with the primary polyphenolic compounds EC and PA2, identified by NMR (Fig. 1B). The rich polyphenolic content of litchi pericarps was first reported in a study by Sarni-Manchado et al (10) and the antioxidant properties of polymeric proanthocyanidins extracted from litchi pericarp have been addressed (16). Flavonoids are able to regulate cellular DNA, RNA and protein synthesis (17).

In the present study, the efficacy of LPE in comparison with silymarin in the recovery of cell viability of $\mathrm{CCl}_{4}(10 \mathrm{nM})$ injured BNL cells in vitro was investigated. As demonstrated in Fig. 2, treatment with $\mathrm{CCl}_{4}$ reduced cell viability to an average of $60 \%$ of that of the untreated (medium only) cell population. Following LPE administration to the $\mathrm{CCl}_{4}$-injured cells for an additional 6-h co-incubation, a dose-dependent trend in the rejuvenation of $\mathrm{CCl}_{4}$-injured $\mathrm{BNL}$ cells was observed. Multiple hepatoprotective mechanisms of silymarin have been demonstrated (18-20), supporting its use as a first-line drug for various symptoms associated with chronic liver injury. Silymarin's primary mechanism of protection is attributed to free radical scavenging. It is understood that silymarin scavenges the $\mathrm{CCl}_{3}$ radical derived from cytochrome P450-metabolised $\mathrm{CCl}_{4}$ (1); however, it has been demonstrated that poor uptake and absorption of silymarin results in only $16 \%$ protection against $\mathrm{CCl}_{4}$-induced liver necrosis (2). LPE containing EC and PA2 exert potent free radical scavenging activities with IC50 $<5 \mu \mathrm{g} / \mathrm{ml}$ (21). The present study has demonstrated that the viability of $\mathrm{CCl}_{4}$-injured $\mathrm{BNL}$ cells is improved more effectively by LPE treatments compared with treatments of silymarin at all levels.

$L P E$ reduces liver inflammation and normalizes serum biomarkers of $\mathrm{CCl}_{4}$-induced liver injury in mice. It has been reported that procyanidin dimers A1, A2 and B2 are readily absorbed through the small intestine of rats, whereas A-type trimers are not absorbed (22). In addition, absorbed PA2 remains in its native form and is not conjugated or methylated (23). In the present study, in vivo evaluation of 
س

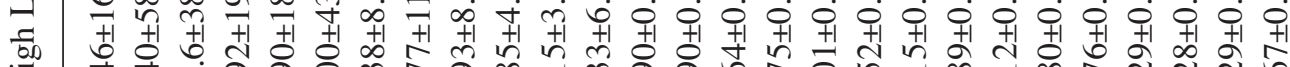

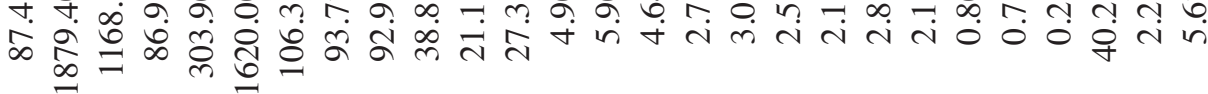

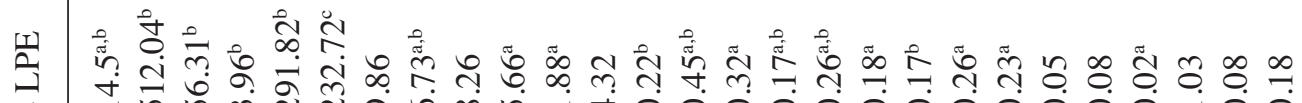

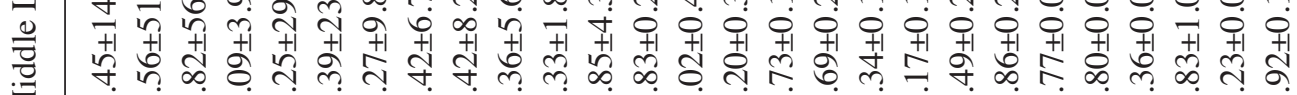

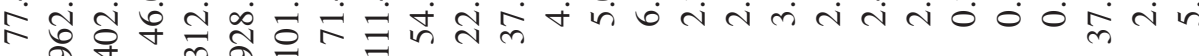

竞

竎究

I

齐

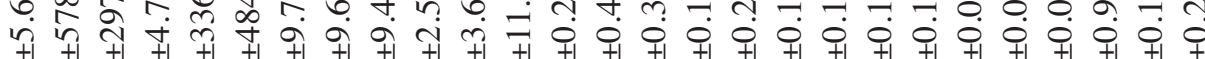

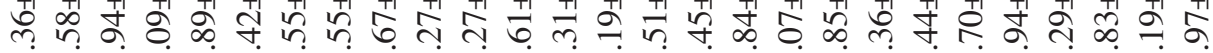
於远

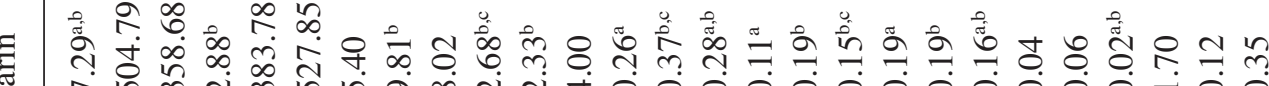

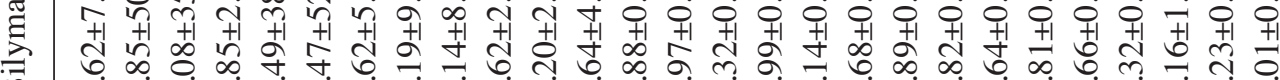

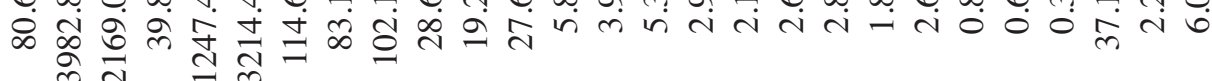

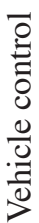

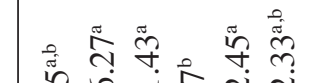

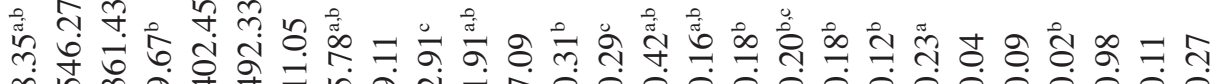

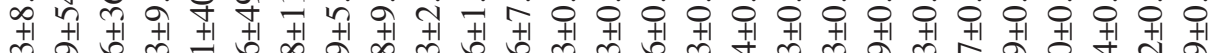

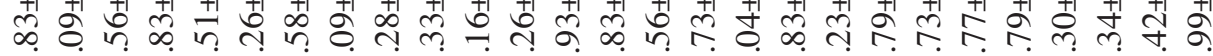
बิं

$-m b-m b-m b-m b-m b-m b-m b-m b$

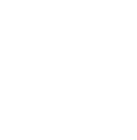

b

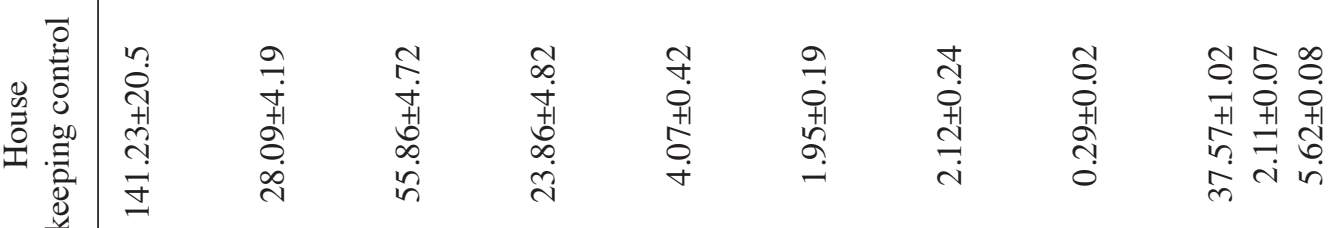


the hepatoprotective effect of LPE rich in EC and PA2 was investigated in comparison with silymarin in a $\mathrm{CCl}_{4}$-induced liver injury mouse model for a duration of 6 weeks. Injection of the chemical toxicant $\mathrm{CCl}_{4}$-induced liver injury, as observed by clinical signs, including the presence of serum biochemical markers of acute hepatitis, early liver tissue necrosis, metabolic dysfunction, chronic signs of hepatic fibrosis and the formation of hepatocellular carcinoma (24). At 6-weeks, $\mathrm{CCl}_{4}$-treated animals gavage-fed with a high dose of LPE $(200 \mathrm{mg} / \mathrm{kg}$ BW/day) exhibited the lowest relative liver weights, whereas animals treated with silymarin and the animals from the $\mathrm{H}_{2} \mathrm{O}$ vehicle-control group demonstrated an increased mean liver weight (Table I), which implied the presence of liver inflammation.

Twice-weekly injections of $\mathrm{CCl}_{4}$-induced sub-acute hepatotoxicity in mice. As demonstrated in Table I, serum GOT levels markedly increased, with levels reaching their peak at 3 weeks. GPT levels increased steadily throughout the 6 weeks in all groups. Silymarin ( $200 \mathrm{mg} / \mathrm{kg}$ BW) administration exhibited a moderate reduction in serum GOT and GPT levels at weeks 1 and 3; however, no long-term effects were observed. Mice gavage-fed daily with LPE with doses between 20 and $200 \mathrm{mg} / \mathrm{kg}$ BW exhibited significantly $(\mathrm{P}<0.05)$ decreased serum GOT and GPT levels compared with those of the silymarin group, and the middle level LPE group, which was fed $100 \mathrm{mg} / \mathrm{kg} \mathrm{BW}$ and LPE, exhibited the most effective protective outcomes. Moreover, the TG level was significantly reduced $(\mathrm{P}<0.05)$ in the $\mathrm{H}_{2} \mathrm{O}$ vehicle-control groups compared with the TG level of the middle and high level LPE groups. By week 3, the TG level of the silymarin group did not significantly differ from that of the $\mathrm{H}_{2} \mathrm{O}$ vehicle-control group; however, the TG level of the silymarin group was significantly lower $(\mathrm{P}<0.05)$ compared with that of all three LPE groups. Pan et al (1) reported that $\mathrm{CCl}_{4}$-induced steatosis resulted from proteosomal degradation of microsomal TG transfer protein, resulting in dysfunctional TG synthesis. Despite the results of the present study indicating that LPE groups had higher serum TG level, all measured values were within the normal range. Liver dysfunction in fatty acid metabolism as the sign of hepatocyte steatosis was only observed in the liver histology. $\mathrm{CCl}_{4}$ may induce liver cell protein synthesis dysfunction, resulting in reduced serum T-p levels. Although the silymarin group exhibited a significantly higher serum T-P level $(\mathrm{P}<0.05)$ than all other groups in the first week, the LPE-treated animals demonstrated normalized serum T-P levels by week 3. Furthermore, calculated results demonstrated that the albumin/globulin $(A / G)$ ratio gradually decreased over the sampling period time in the $\mathrm{H}_{2} \mathrm{O}$ vehicle-control group, indicating a gradual increase in the severity of $\mathrm{CCl}_{4}$-induced hepatotoxicity (data not shown). In general, low-level LPE (20 mg/kg BW) treatment demonstrated promising results in retaining a relatively unchanged $A / G$ ratio compared with the other LPE groups. Obstructed bile formation is frequently observed in chronic liver diseases along with increasing serum bilirubin level. By week 6 , an overall reduction of T-bili was observed in all groups, which may be a result of physiological compensation. Further investigations are required to confirm this.

Liver gross anatomy and histological assessments affected by LPE. Macroscopic examination of the largest transverse

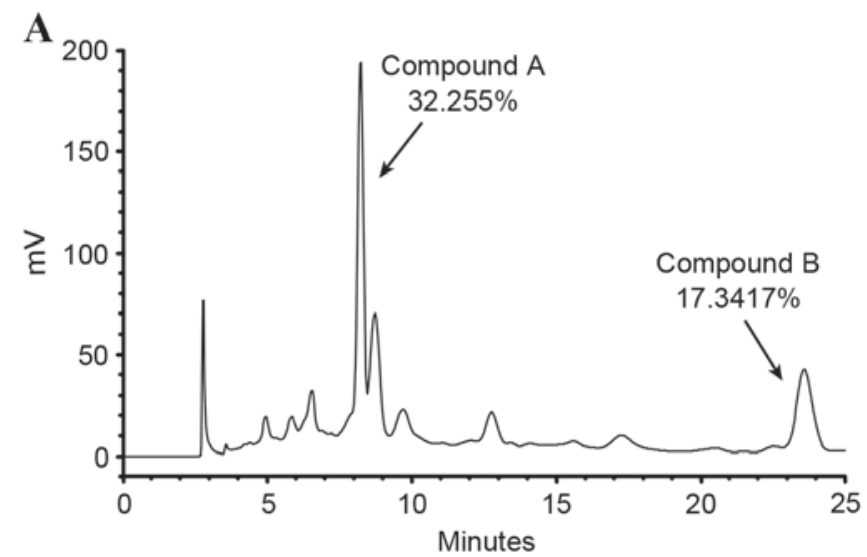

B<smiles>Oc1cc(O)c2c(c1)O[C@H](c1ccc(O)c(O)c1)C[C@H]2O</smiles>

Compound A Epicatechin $\mathrm{C}_{15} \mathrm{H}_{14} \mathrm{O}_{6}$

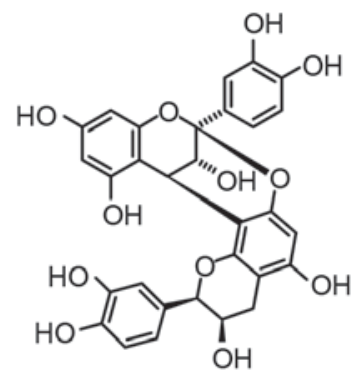

Compound $B$ Procyanidin $\mathrm{A}$ $\mathrm{C}_{30} \mathrm{H}_{24} \mathrm{O}_{12}$
Figure 1. Sample chromatogram of the D40M fraction of LPE detected by high-performance liquid chromatography. (A) Primary compounds in LPE identified by nuclear magnetic resonance. (B) Compound $\mathrm{A}$ is epicatechin $\mathrm{C}_{15} \mathrm{H}_{14} \mathrm{O}_{6}$ (MW, 290.27) and compound $\mathrm{B}$ is procyanidin $\mathrm{A} 2 \mathrm{C}_{30} \mathrm{H}_{24} \mathrm{O}_{12}$ (MW, 576.50). LPE, litchi pericarp extract; MW, molecular weight.

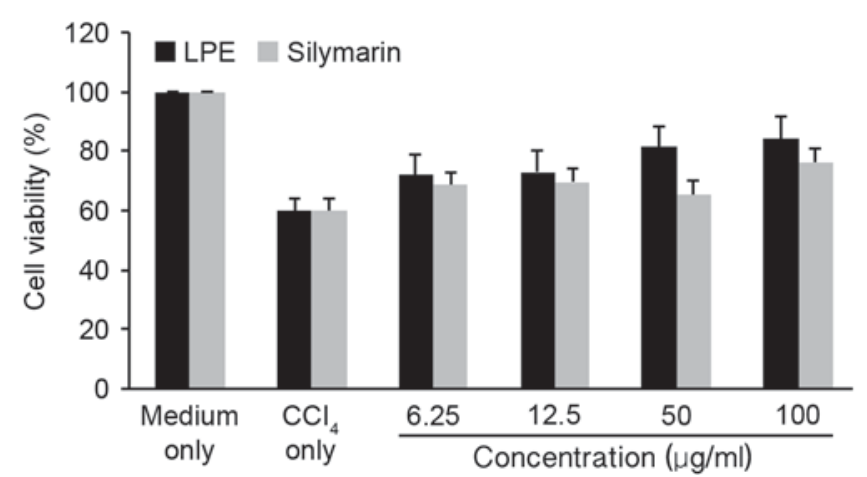

Figure 2. Effect of LPE on recovery of cell viability in low-level $\mathrm{CCl}_{4}$ $(10 \mathrm{nM})$ injured BNL CL2 liver cells in vitro. Data are expressed as the mean \pm standard deviation of at least three independent experiments. LPE dose-dependently rescued cell viability more effectively than silymarin, at all levels. LPE, litchi pericarp extract; $\mathrm{CCl}_{4}$, carbon tetrachloride.

plane section of the primary liver lobule (lobus sinister lateralis hepatis), allowing observation of the central portal veins and bile ducts, was performed. The outer appearance of the entire caudal lobe was examined after formaldehyde fixation, as exhibited in the left column of Fig. 3. Under $\mathrm{CCl}_{4}$ intoxication, high-level LPE treatment preserved the smooth outer capsule, similar to that observed in the liver from normal control mice. The cross section of the primary liver lobes demonstrated 
Table II. LPE rescued $\mathrm{CCL}_{4}$-induced liver injury by preserving the glutathione antioxidative system.

\begin{tabular}{lcr} 
Groups & GSH peroxidase $(\mathrm{nmol} / \mathrm{min} / \mathrm{ml})$ & GSH reductase $(\mathrm{nmol} / \mathrm{m}$ \\
\hline Normal control & $70.19 \pm 3.37^{\mathrm{c}}$ & $233.51 \pm 25.18^{\mathrm{a}, \mathrm{b}}$ \\
$\mathrm{H}_{2} \mathrm{O}$ vehicle & $61.42 \pm 2.98^{\mathrm{d}}$ & $174.04 \pm 27.24^{\mathrm{d}}$ \\
Silymarin & $75.95 \pm 5.06^{\mathrm{a}, \mathrm{b}}$ & $218.86 \pm 20.69^{\mathrm{b}, \mathrm{c}}$ \\
Low LPE $(20 \mathrm{mg} / \mathrm{kg} \mathrm{BW})$ & $82.21 \pm 1.32^{\mathrm{a}}$ & $180.20 \pm 38.41^{\mathrm{c}, \mathrm{d}}$ \\
Middle LPE $(100 \mathrm{mg} / \mathrm{kg} \mathrm{BW})$ & $68.93 \pm 3.02^{\mathrm{c}}$ & $193.03 \pm 39.18^{\mathrm{c}}$ \\
High LPE $(200 \mathrm{mg} / \mathrm{kg} \mathrm{BW})$ & $72.73 \pm 7.39^{\mathrm{b}, \mathrm{c}}$ & $265.24 \pm 48.78^{\mathrm{a}}$
\end{tabular}

Data are presented as mean \pm standard deviation $(\mathrm{n}=8)$. ${ }^{\mathrm{a}, \mathrm{b}, \mathrm{c}, \mathrm{d}}$ represent the comparisons among treatments in the same column, with different superscripts indicating significant differences at $\mathrm{P}<0.05$. Mice were injected with $\mathrm{CCl}_{4}$ twice weekly, apart from mice in the normal control group, and subjected to daily gavage-feeding of the same volume of either $\mathrm{H}_{2} \mathrm{O}$ or silymarin $(200 \mathrm{mg} / \mathrm{kg} \mathrm{BW})$, or a low level (20 mg/kg BW), middle level $(100 \mathrm{mg} / \mathrm{kg} \mathrm{BW})$ or high level dose $(200 \mathrm{mg} / \mathrm{kg} \mathrm{BW})$ of LPE. LPE, litchi pericarp extract; GSH, glutathione; CCl ${ }_{4}$, carbon tetrachloride; BW, body weight; NC, normal house-keeping control group.

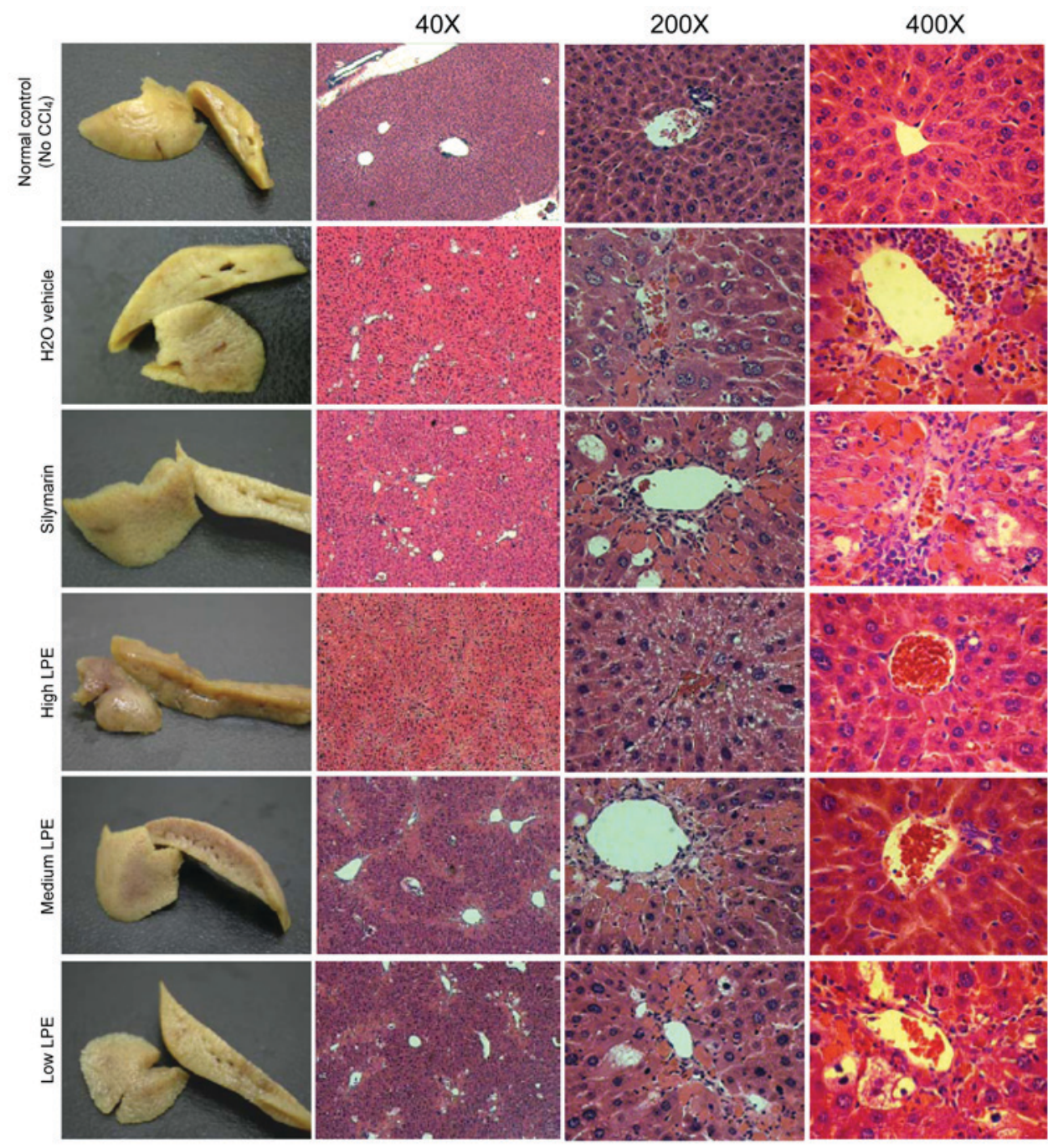

Figure 3. The gross appearance and microscopic histopathology (haematoxylin and eosin staining; magnification, x40, x200, and x400) of liver tissue from the normal animal group (control) and treatment groups of silymarin, $\mathrm{H}_{2} \mathrm{O}$, high-dose LPE (200 mg/kg BW/day), middle-dose LPE (100 mg/kg BW/day), and low-dose LPE (20 mg/kg BW/day) in mice with $\mathrm{CCl}_{4}$-induced liver injury. Based on the gross appearance of the liver, the normal and high LPE groups had similar smooth outer capsules compared with those of other groups. Histopathological analysis demonstrated the hepatocyte edges formed pentagonal lobule architecture were retained in all treatments; however, steatosis can be seen in the silymarin, $\mathrm{H}_{2} \mathrm{O}$, medium-LPE and low-LPE groups (magnification, $\mathrm{x} 40$ ). $\mathrm{CCl}_{4}$-intoxication resulted in swollen hepatocytes and impaired lipid synthesis, resulting in the formation of a fatty vacuole (macrosteatosis) in the low-level LPE, silymarin and $\mathrm{H}_{2} \mathrm{O}$ vehicle-control groups (magnification, x200). Furthermore, eosinophil infiltration (eosinophilia) along the central portal veins extending to the lobular venous tract and dark-purple/blue stained Kupffer cells infiltration along the central portal vein were evident in the in the low-LPE, silymarin and $\mathrm{H}_{2} \mathrm{O}$ groups. However, fewer focal observations were noted in the middle and high-LPE samples (magnification, $\mathrm{x} 400$ ). LPE, litchi pericarp extract; $\mathrm{BW}$, body weight; $\mathrm{CCl}_{4}$, carbon tetracholoride. 


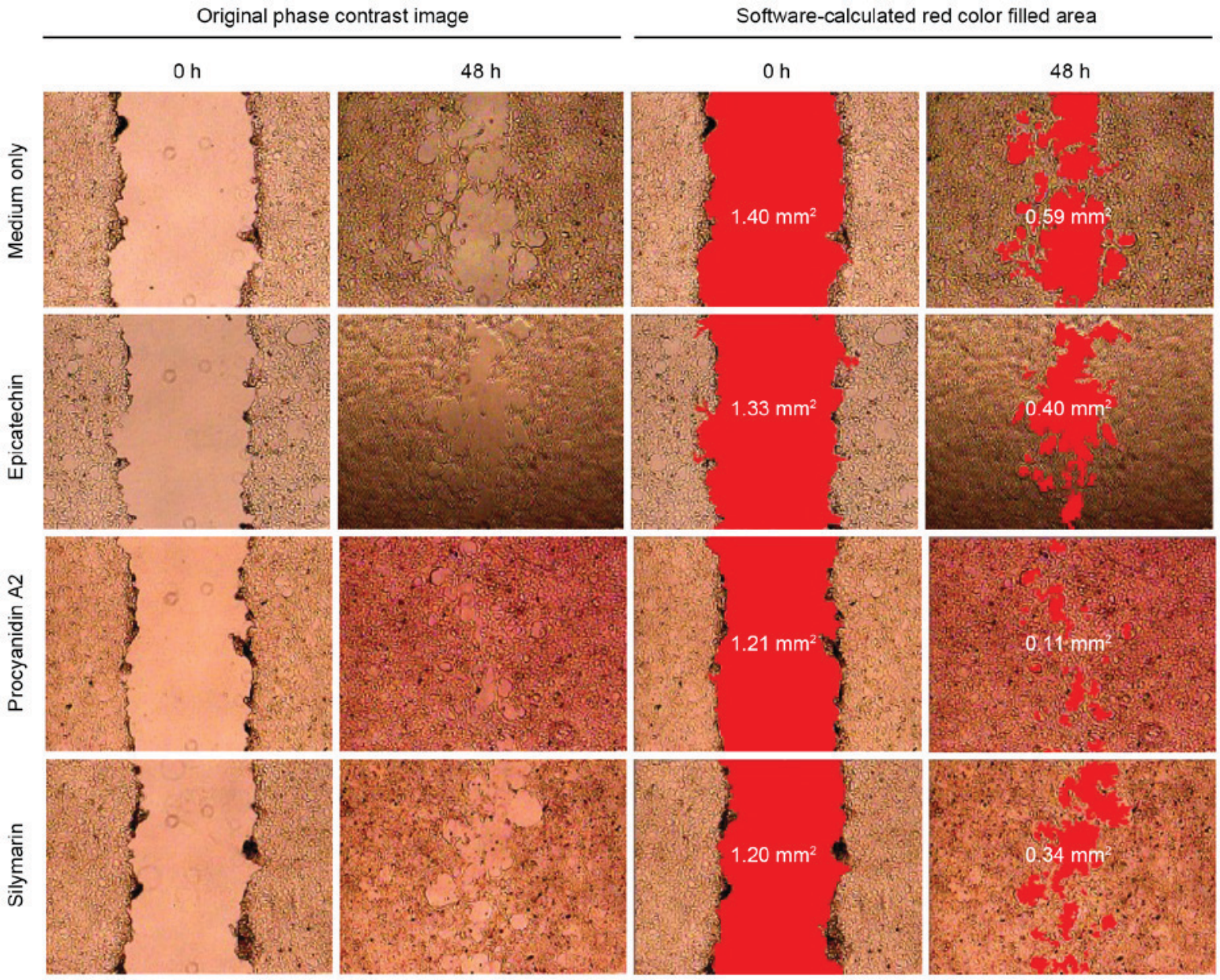

Figure 4. BNL CL2 murine embryonic liver cell recovery with the scratch wound healing assay. The scratch area and the gap recovery were quantitatively analyzed (red colour filled in the cell-free gap). The results demonstrate that cells treated with procyanidin A2 had averagely improved wound recovery than those treated with either epicatechin or silymarin. The data represent one of five independent trials.

no sign of focal hepatic lesion in any group. Evidence of a swollen liver in the sectional views of the silymarin, $\mathrm{H}_{2} \mathrm{O}$ vehicle-control and low-LPE groups was observed. In addition, the rough segmental outer appearance and fibrotic septa were less apparent in the high-level LPE and normal control groups compared with all other groups. Furthermore, the central venous architectures in the middle of the cross section of the primary liver lobe were readily observed in the $\mathrm{H}_{2} \mathrm{O}$ vehicle-control and the low-level LPE groups; however, they were not clearly observed in the silymarin, middle or high-level LPE groups. The results of the present study demonstrated that LPE containing rich procyanidins reduced hepatic fibrosis, similar to the effects of procyanidins found in grape seed (25).

Histopathological assessments were performed, as exhibited in microscopic sections in Fig. 3. When examined at lower magnification (x40), fewer lipid droplet holes or spaces were observed in the high-level LPE group compared with all other groups. The portal area of hexagonal architecture, formed by aligning hepatocyte edges, was retained in all treatment groups. White fibrotic connective tissues surrounding the portal vein areas extending along the sinusoid was clearly observed in the silymarin and $\mathrm{H}_{2} \mathrm{O}$ vehicle-control groups, indicating early liver cirrhosis. Eosinophilia (red colour stain) was observed in all tissue sections of $\mathrm{CCl}_{4}$-induced hepatotoxicity (magnification, x200). The high-level LPE group exhibited less eosinophilic infiltration than the other groups. Eosinophilic infiltration is an early sign of chronic inflammation and results in chemotaxis of interleukin 5 secreted from Kupffer cells (26). Further investigation is required to determine whether LPE may exhibit immunomodulatory potential.

Additionally, differing severities of steatosis were observed in all groups of $\mathrm{CCl}_{4}$-intoxication, as indicated by the white arrowheads in Fig. 3. Macrosteatosis was clearly observed in the silymarin, low-level LPE and $\mathrm{H}_{2} \mathrm{O}$ vehicle-control groups (magnification, $\mathrm{x} 200$ ), whereas steatosis was less evident along the portal vein area of the middle and high-level LPE groups. Furthermore, infiltrated darker, dense nuclei-stained Kupffer cells were clearly observed in the sinusoids of the $\mathrm{H}_{2} \mathrm{O}$, silymarin and low-LPE groups. It is understood that Kupffer cells are responsible for multiple mediators in the activation of stellate cells, which induce liver fibrosis (27). The in situ results of the present study have posed additional questions on modulatory properties of LPE in the healing process of Kupffer cells and eosinophils.

LPE upregulates antioxidative enzyme activity in the liver. The antioxidative activity of liver tissues is facilitated by multiple enzymatic systems. The glutathione system governs lipid integrity by scavenging radicals for transfer to nicotinamide adenine dinucleotide phosphate (28). Studies have demonstrated 
$\mathbf{A}$
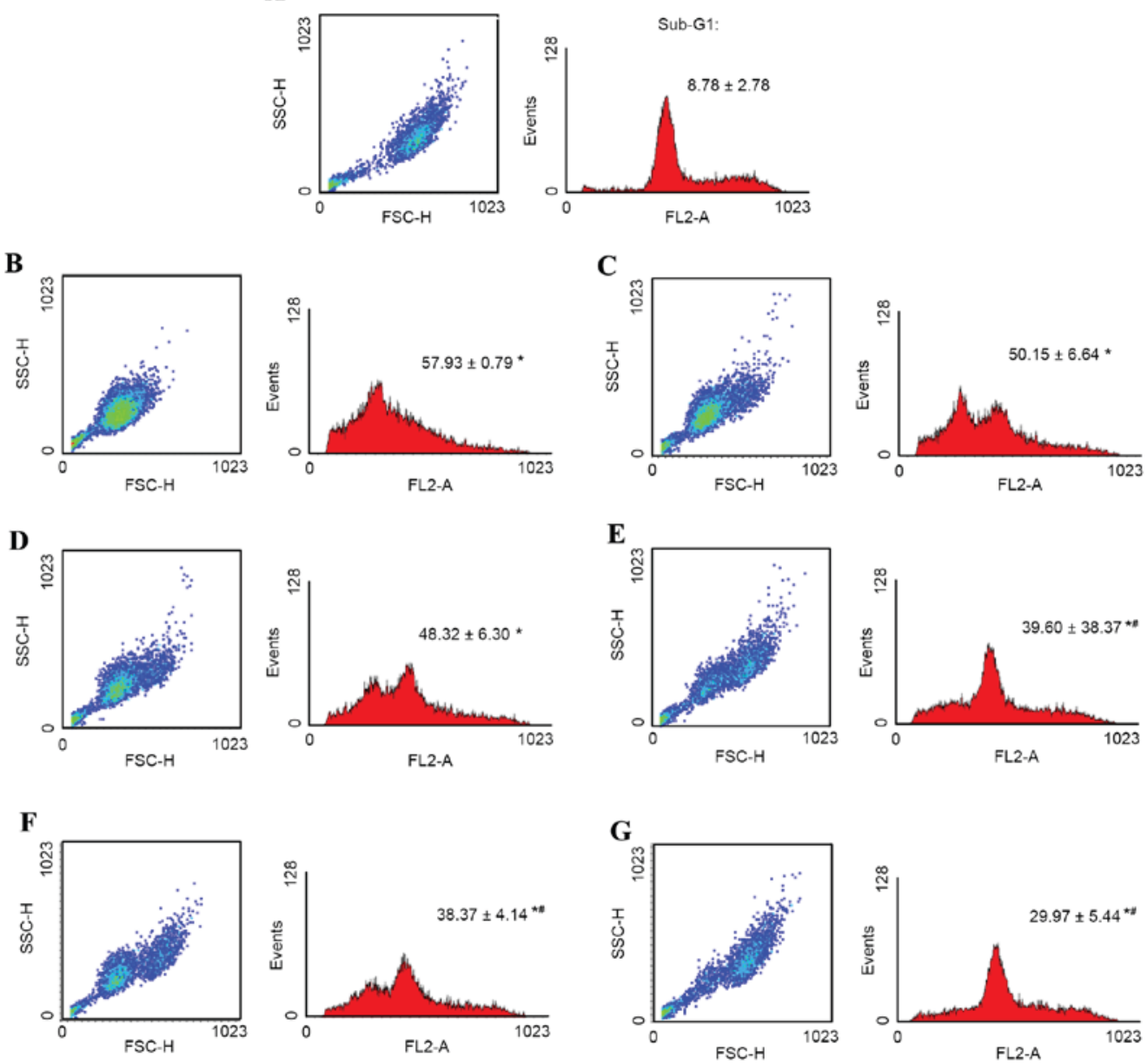

Figure 5. Cell integrity, cell cycle and quantified sub-G1 phase of alcohol-injured BNL murine embryonic liver cells treated with PA2. Cells were protected dose-dependently by PA2. All samples were pre-treated with $10 \%$ alcohol for $1 \mathrm{~h}$, except for the (A) negative control sample. The alcohol-containing medium was then replaced with fresh medium with either (B) 0, (C) 1, (D) 5, (E) 10, (F) 25 or (G) $50 \mu \mathrm{g} / \mathrm{ml} \mathrm{PA2} \mathrm{for} \mathrm{an} \mathrm{additional} \mathrm{24-h} \mathrm{culture.} \mathrm{Cell} \mathrm{integrity} \mathrm{(dot} \mathrm{plot;}$ $\mathrm{x}$-axis, cell-size; $\mathrm{y}$-axis, granularity) and accumulated DNA content (histogram plot) of cell cycle were obtained by flow cytometry. PA2 dose-dependently reduced the proportion of sub-G1 phase cells (quantitative data value) and normalized cell-integrity. The sub-G1 values are presented as mean \pm standard deviation, $\mathrm{n}=3$. ${ }^{\mathrm{P}} \mathrm{P}<0.05$ vs. negative control group; ${ }^{*} \mathrm{P}<0.05$ vs. alcohol-containing medium group; PA2, procyanidin A2.

that phenolic compounds are able bind to antioxidant response elements and increase the gene transcription of antioxidant enzymes in the liver $(29,30)$. The present study exhibited that both GSHpx and GSHred activity were rescued by silymarin or LPE administration; however, the vehicle group treated with $\mathrm{H}_{2} \mathrm{O}$ only demonstrated diminished GSHpx and GSHred activity as a result of $\mathrm{CCl}_{4}$-intoxication (Table II). The high-level LPE group exhibited a similar GSHred activity to that of normal control mice, which was significantly higher $(\mathrm{P}<0.05)$ than the silymarin group. Potent free radical scavenging activity of litchi pericarp polyphenols, EC and procyanidins, in the 2, 2-diphenyl-1-picrylhydrazyl assay has been reported (31). In the present study, ex vivo analysis of liver antioxidative enzyme systems demonstrated that LPE dramatically preserved hepatic GSHred activity, supporting other studies on hepatoprotective antioxidants $(32,33)$.

PA2 isolated from LPE promotes scratch wound healing and rescues alcohol-injured BNL CL2 liver cells. To further elucidate the functional mechanisms of LPE, and its containing EC and PA2, in association to injured-liver recovery, the scratch wound healing assay was utilized to assess their effects on cell migration, growth and proliferation. By quantitative analysis of the recovery of the scratch wound gap, it has been reported that the silibinin in milk thistle fractions has protective and curative effects on liver damage (34). In the present study, the BNL cells in culture medium with EC, PA2 or silymarin exhibited smaller cell-free areas than that of the control group BNL cells in culture medium only (Fig. 4). PA2 treatment resulted in the fastest scratch wound healing.

Furthermore, in order to determine whether accelerated wound healing activity by PA 2 could result from an increase in cell proliferation, and decreased cell apoptosis, the present study analyzed the cell cycle of PA2-treated alcohol-injured BNL cells in vitro. Alcohol exposure may result in increased mitochondrial production of reactive oxygen species in liver cells (35). In the present study, BNL cells treated with ethanol exhibited free radical damage, resulting in cell oxidative stress. Under these circumstances, cells underwent apoptosis and the cell cycle was halted. BNL cells retracted for detoxification and DNA repairing, as exhibited in cell scatter (SSC vs. FSC) dot plots in a condensed population (Fig. 5). Furthermore the histogram of cell cycle analysis demonstrated a significant dose-dependent reduction of cells in sub-G1 phase with 
increasing PA2 levels $(\mathrm{P}<0.05)$. Additionally, high-level PA2 $(50 \mu \mathrm{g} / \mathrm{ml})$ treatment demonstrated accelerated self-repairing of injured BNL cells by retaining the G1 and cell mitosis phases of the cell cycle.

In conclusion, chemically identified LPE rich in EC and PA2 are understood to be potent antioxidants. LPE gavage-fed to $\mathrm{CCl}_{4}$-intoxicated mice resulted in the recovery of normalized serum biochemical and GSHred levels in the liver. Liver histopathological assessments demonstrated that LPE was more effective than silymarin at reducing liver steatosis and fibrosis. Both EC and PA2 of LPE were able to accelerate cell recovery in injured liver cells. PA2 exhibited superior liver protection compared to EC and silymarin. The findings of the present study support the traditional Chinese herbal medical practice of prescribing litchi as a tonic ingredient for the treatment of liver damage.

\section{Acknowledgements}

The present study was supported by internal funding from the National Chiayi University and partial financial support was provided by the Council of Agriculture, Taiwan (grant no. 992101010503-030103Z1).

\section{References}

1. Pan X, Hussain FN, Lqbal J, Feuerman MH and Hussain MM Inhibiting proteasomal degradation of microsomal triglyceride transfer protein prevents $\mathrm{CCl} 4$-induced steatosis. J Biol Chem 282: 17078-17089, 2007.

2. Pradhan SC and Girish C: Hepatoprotective herbal drug, silymarin from experimental pharmacology to clinical medicine. Indian J Med Res 124: 491-504, 2006.

3. Yang Z, Zhuang L, Lu Y, Xu Q and Chen X: Effects and tolerance of silymarin (Milk thistle) in chronic hepatitis $\mathrm{C}$ virus infection patients: A meta-analysis of randomized controlled trials. Biomed Res Int 2014: 941085, 2014.

4. Joseph A and Knight A: Criss call for new preventive medicine: Emerging effects of lifestyle on morbidity and mortality Published by World Scientific Publishing Co. Pte. Ltd. ISBN 981-238-700-5, in pp632-634 2004.

5. Yousef MI, Saad AA and El-Shennawy LK: Protective effect of grape seed procyanidin extract against oxidative stress induced by cisplatin in rats. Food Chem Toxicol 47: 1176-1183, 2009.

6. Domitrović $\mathrm{R}$ and Jakovac $\mathrm{H}$ : Antifibrotic activity of anthocyanidin delphinidin in carbon tetrachloride-induced hepatotoxicity in mice. Toxicology 272: 1-10, 2010.

7. Chiu NY and Chang KH: The illustrated medicinal plants of Taiwan, 'SMC Publishing, Inc. Taipei, Taiwan ROC, pp129, 1986.

8. Besra SE, Sharma RM and Gomes A: Antiinflammatory effect of petroleum ether extract of leaves of litchi chinensis Gaertn. (Sapindaceae). J Ethnopharmacol 54: 1-6, 1996.

9. Wang X, Yuan S, Wang J, Lin P, Liu G, Lu Y, Zhang J, Wang W and Wei Y: Anticancer activity of litchi fruit pericarp extract against human breast cancer in vitro and in vivo. Toxicol Appl Pharmacol 215: 168-178, 2006.

10. Sarni-Manchado P, Le Roux E, Le Guernevé C, Lozano Y and Cheynier V: Phenolic composition of litchi fruit pericarp. J Agric Food Chem 48: 5995-6002, 2000.

11. Liu L, Cao S, Xu Y, Zhang M, Xiao G, Deng Q and Xie B: Oxidation of (-)-epicatechin is a precursor of litchi pericarp enzymatic browning. Food Chem 118: 508-511, 2010.

12. Chang CW: Identification and investigation on the hepatoprotective properties of the pericarps extract of Litchi (Chinensis Sonn). (unpublished PhD thesis). National Chiayi University, Taiwan, ROC., 2009.

13. Weng BB, Lin WS, Chang JC and Chiou RY: The phytoestrogenic stilbenes, arachidin-1 and resveratrol, modulate regulatory T cell functions responsible for successful aging in aged ICR mice. Int J Mol Med 38: 1895-1904, 2016.
14. Liang CC, Park AY and Guan JL: In vitro scratch assay: A convenient and inexpensive method for analysis of cell migration in vitro. Nat Protoc 2: 329-333, 2007.

15. Quimby FW and Luong RH: Clinical chemistry of the laboratory mouse. In: Fox JG, Davisson M, Qunimby F, Barthold S, Newcomer C, Smith A, eds. The Mouse in Biomedical Research. $2^{\text {nd }}$ ed. Elsevier; 117-216, 2007

16. Zhou HC, Lin YM, Li YY, Li M, Wei SD and Chai WM and Tam NF: Antioxidant properties of polymeric proanthocyanidins from fruit stones and pericarps of litchi chinensis Sonn. Food Res Int 44: 613-620, 2011.

17. Hirano T, Gotoh M and Oka K: Natural flavonoids and lignans are potent cytostatic agents against human leukaemic HL-60 cells. Life Sci 55: 1061-1069, 1994.

18. Dixit N, Baboota S, Kohli K, Ahmad S and Ali J: Silymarin: A review of pharmacological aspects and bioavailability enhancement approaches. Indian J Pharmacol 39: 172-179, 2007.

19. Kim M, Yang SG, Kim JM, Lee JW, Kim YS and Lee JI: Silymarin suppresses hepatic stellate cell activation in a dietary rat model of non-alcoholic steatohepatitis: Analysis of isolated hepatic stellate cells. Int J Mol Med 30: 473-479, 2012.

20. Surai PF: Silymarin as a natural antioxidant: An overview of the current evidence and perspectives. Antioxidants (Basel) 4: 204-247, 2015

21. Liu L, Xie B, Cao S, Yang E, Xu X and Guo S: A-type procyanidins from litchi chinensis pericarps with antioxidant activity. Food Chem 105: 1446-1451, 2007

22. Appeldoorn MM, Vincken JP, Gruppen H and Hollman PC: Procyanidin dimers A1, A2, and B2 are absorbed without conjugation or methylation from the small intestine of rats. J Nutr 139: 1469-1473, 2009.

23. Ma Q, Xie H, Li S, Zhang R, Zhang M and Wei X: Flavonoids from the pericarps of litchi chinensis. J Agric Food Chem 62: 1073-1078, 2014.

24. Plaa GL: Chlorinated methanes and liver injury: Highlights of the past 50 years. Annu Rev Pharmacol Toxicol 40: 42-65, 2000.

25. Dulundu E, Ozel Y, Topaloglu U, Toklu H, Ercan F, Gedik N and Sener G: Grape seed extract reduces oxidative stress and fibrosis in experimental biliary obstruction. J Gastroenterol Hepatol 22: 885-892, 2007.

26. Tsuda K, Maeda T, Tominaga A, Watanabe Y, Miyazaki E, Enzan H, Akisawa N, Iwasaki S, Saibara T and Onishi S: Eosinophil-induced liver injury: An experimental model using IL-5 transgenic mice. J Hepatol 34: 270-277, 2001.

27. Roberts RA, Ganey PE, Ju C, Kamendulis LM, Rusyn I and Klaunig JE: Role of the kupffer cell in mediating hepatic toxicity and carcinogenesis. Toxicol Sci 96: 2-15, 2007.

28. Bienert GP, Schjoerring JK and Jahn TP: Membrane transport of hydrogen peroxide. Biochim Biophys Acta 1758: 994-1003, 2006.

29. Han X, Shen T and Lou H: Dietary polyphenols and their biological significance. Int J Mol Sci 8: 950-988, 2007.

30. Martin MA, Grando Serrano AB, Ramos S, Pulido MI, Bravo L and Goya L: Cocoa flavonoids up-regulated antioxidant enzyme activity via the ERK1/2 pathway to protect against oxidative stress-induced apoptosis in HepG2 cells. J Nutri Biochem 21: 196-205, 2010.

31. Castellain RC, Gesser M, Tonini F, Schulte RV, Demessiano KZ, Wolff FR, Delle-Monache F, Netz DJ, Cechinel-Filho V, de Freitas RA, et al: Chemical composition, antioxidant and antinociceptive properties of litchi chinensis. J Pharm Pharmacol 66: 1796-1807, 2014

32. Dai N, Zou Y, Zhu L, Wang HF and Dai MG: Antioxidant properties of proanthocyanidins attenuate carbon tetrachloride $(\mathrm{CCl} 4)$-induced steatosis and liver injury in rats via CYP2E1 regulation. J Med Food 17: 663-669, 2014.

33. Yang BY, Zhang XY, Guan SW and Hua ZC: Protective effect of procyanidin B2 against CCl4-induced acute liver injury in mice. Molecules 20: 12250-12265, 2015.

34. Yarrow JC, Perlman ZE, Westwood NJ and Mitchison TJ: A high throughput cell migration assay using scratch wound healing, a comparison of image-based readout method. BMC Biotechnol 4: 21, 2004.

35. Bailey SM and Cunningham CC: Acute and chronic ethanol increase reactive oxygen species generation and decreases viability in fresh, isolated rat hepatocytes. Hepatology 28 : 1318-1326, 1998. 